\title{
Risk Factors for Low Birth Weight Infants in Japanese Pregnancies: A One-year Study of 2551 Cases in Tokyo
}

\author{
Kaori Arima $^{1,2}$, Yasuyo Kasai ${ }^{2}$, Mitsuhiro Sugimoto ${ }^{2}$, Eiji Marui ${ }^{3,4}$ and Kazuo Minematsu ${ }^{4,5^{*}}$ \\ ${ }^{1}$ Department of Public Health, Juntendo University Graduate School of Medicine, Tokyo, Japan \\ ${ }^{2}$ Department of Obstetrics and Gynecology, Japanese Red Cross Medical Center, Tokyo, Japan \\ ${ }^{3}$ Faculty of Human Science, University of Human Arts and Sciences, Saitama, Japan \\ ${ }^{4}$ Department of Public Health, Juntendo University School of Medicine, Tokyo, Japan \\ ${ }^{5}$ Department of School Health, Graduate School of Education, Nagasaki University, Nagasaki, Japan
}

\begin{abstract}
Background: The rate of low-birth weight infants in Japan has been increasing. Being underweight and increasing maternal age are risk factors for delivering low birthweight infants. Currently, pregnant Japanese women exhibit these risk factors for delivering low birthweight infants; however, little research has been conducted. This study aimed to investigate the associations between pregnancy characteristics in Japanese women and low birth weight infants.

Methods: We enrolled 2551 pregnant women at $>36$ weeks of gestation and who delivered in metropolitan Tokyo. Pre-pregnancy body mass index was categorized using the World Health Organization classification. Gestational weight gain and birth weight were categorized based on the guidelines of the Ministry of Health, Labour and Welfare, Japan. The differences in pregnancy characteristics among three birth-weight categories,i.e., low birth weight, normal, and macrosomia, were assessed using the chisquare test. The risk ratios of low birth weight were estimated using logistic regression analysis.

Results: In Japanese pregnancies, birth weight was associated with gestational week at delivery, gestational weight gain, pre-pregnancy body mass index, sex, parity, and maternal age $(\mathrm{P}<0.05)$. In particular, the risk of low birth weight increased with advanced maternal age (odds ratio=1.97), insufficient gestational week at delivery (odds ratio=9.00), low gestational weight gain (odds ratio=2.76), and female infant (odds ratio=2.06). Further, it decreased in multiparous women compared with that in primiparous women (odds ratio $=0.57$ ).

Conclusions: These findings suggest that pregnant Japanese women who are $\geq 40$ years old with a gestational weight gain of $<7.0 \mathrm{~kg},<37$ gestational weeks at delivery, female baby, and primiparous should be checked carefully during the gestational period. In order to decrease the risk of low birth weight babies, women should be educated early about childbearing and pregnancy.
\end{abstract}

\section{Introduction}

Low pre-pregnancy body mass index (BMI) is a significant risk factor for delivering low-birth weight (LBW) infants [1,2]. Gestational weight gain (GWG) and gestational week at delivery (GWD) are also crucial for preventing the delivery of LBW infants $[1,2]$. Underweight pregnant women are at a particularly increased risk of preterm delivery and delivering small for gestational age (SGA) and LBW infants [3]. In Japan, the ratio of underweight women, especially in their 20s and 30s, has increased dramatically. In 1982, the proportion of underweight Japanese women in their 20s and 30s was $12.1 \%$ and $8.2 \%$, respectively, and in 2012 , these rates had increased to $21.8 \%$ and $17.1 \%$, respectively $[4,5]$. Since the 1970 s, a consistent increase in the proportion of LBW infants has been observed [6].

Adequate GWG during pregnancy is crucial for avoiding complications in both mothers and their children [1-3]. In 2006, the Ministry of Health, Labour and Welfare (MHLW) of Japan defined suitable levels of GWG in pregnant Japanese women based on pre-pregnancy BMI to ensure healthy birth weights $(3000 \mathrm{~g})$ as $9.0-12.0 \mathrm{~kg}$ for underweight women $\left(<18.5 \mathrm{~kg} / \mathrm{m}^{2}\right), 7.0-12.0 \mathrm{~kg}$ for normal weight women $\left(18.5-24.9 \mathrm{~kg} / \mathrm{m}^{2}\right)$, and $5.0 \mathrm{~kg}$ for overweight women $\left(\geq 25 \mathrm{~kg} / \mathrm{m}^{2}\right)$ [7]. GWG in pregnant Japanese women is strictly managed following this guideline. However, the mean birth weight (BW) of singletons decreased from $3200 \mathrm{~g}$ in 1975 to $3020 \mathrm{~g}$ in 2009. In 2009, the rate of LBW infants in Japan reached a peak of 8.3\% [8].

\section{Publication History:}

Received: February 27, 2017

Accepted: March 28, 2017

Published: March 30, 2017

\section{Keywords:}

Advanced maternal age, Maternal underweight, Gestational weight gain, Low birth weight
One of the most striking changes in the demography of developed countries during the last decades has been the postponement of childbirth until women are in their late 30s [9]. Increasing maternal age at first delivery is an independent risk factor for LBW infants in the United States of America (USA) [10].Both black and white mothers in their 30 s are significantly more likely to deliver a LBW infant than women aged 25-29 years [11]. In Japan, the mean age at first birth was 25.7 years in 1975 and 30.3 years in 2012, and maternal age in Japan has also increased rapidly [5].

Therefore, we hypothesize that currently, Japanese women exhibit three risk factors for delivering LBW babies: insufficient GWG, underweight maternal status, and advanced maternal age at delivery. Little research has been conducted on the associations between birth and older mothers despite the increasing rates of LBW infants in Japan $[6,12]$. The objective of this study was to assess the association

"Corresponding Author: Prof. Kazuo Minematsu, Department of School Health, Graduate School of Education, Nagasaki University, Nagasaki, Japan, Tel: +8195-819-2359; E-mail: minematsu@nagasaki-u.ac.jp

Citation: Arima K, Kasai Y, Sugimoto M, Marui E, Minematsu K (2017) Risk Factors for Low Birth Weight Infants in Japanese Pregnancies: A One-year Study of 2551 Cases in Tokyo. Int J Pediatr Neonat Care 2: 119. doi: https://doi. org/10.15344/2455-2364/2017/122

Copyright: (c) 2016 Arima et al. This is an open-access article distributed under the terms of the Creative Commons Attribution License, which permits unrestricted use, distribution, and reproduction in any medium, provided the original author and source are credited. 
Citation: Arima K, Kasai Y, Sugimoto M, Marui E, Minematsu K (2017) Risk Factors for Low Birth Weight Infants in Japanese Pregnancies: A One-year Study of 2551 Cases in Tokyo. Int J Pediatr Neonat Care 2: 119. doi: https://doi.org/10.15344/2455-2364/2017/122

Page 2 of 6

between maternal characteristics and BW after controlling for other maternal factors. Previous studies have suggested combined effects of pre-pregnancy BMI, GWG, GWD, parity, and infant gender in relation to LBW [1-3,6,12-15]. Furthermore, we evaluated the rates at which women below, within, and above MHLW guidelines delivered normal weight infants, including combined effects, using odds ratios (ORs) and 95\% confidence intervals (95\% CI). This study contributes to the existing Japanese literature by providing new information that underscores the need to balance pregnancy characteristics and MHLW guidelines against the risk of LBW.

\section{Materials and Methods}

\section{Participants}

This study was a comprehensive analysis of pregnancy data obtained from the Japanese Red Cross Medical Centre in Tokyo, Japan (JRC) in 2011. A total of 2847 pregnant women delivered at the JRC between January and December 2011 with 2567 singletons born after 36 weeks of gestation. After excluding cases with missing data, 2551 deliveries from singleton pregnancies after 36 weeks of gestation were enrolled in the study. Pregnant smokers cannot give birth at this medical center and therefore, all participants in this study were non smokers.

\section{Instruments}

All information was obtained from objective records and included demographic characteristics, medical history, and pre- and postnatal visits.

\section{Data collection}

The demographic characteristics of the pregnant women, including maternal age, pre-pregnancy BMI values $\left(\mathrm{kg} / \mathrm{m}^{2}\right)$, GWG, parity, and GWD were collected from the medical records of the women. Infant data, including BW and gender, were also collected. Pregnancy BMI was categorized into three groups based on the World Health Organization (WHO) classifications: underweight $\left(<18.5 \mathrm{~kg} / \mathrm{m}^{2}\right)$, normal weight (18.5-24.9 kg/m²: reference), and overweight ( $\geq 25 \mathrm{~kg} /$ $\mathrm{m}^{2}$ ). GWG was defined as the difference in kilograms between the measured weight on admission for delivery or the last prenatal visit (within one week before delivery) and the weight before becoming pregnant. GWG was categorized according to the 2006 guidelines of the MHLW of Japan as low $(<7.0 \mathrm{~kg})$, almost appropriate $(7.0-8.9 \mathrm{~kg})$, appropriate (reference: $9.0-11.9 \mathrm{~kg}$ ), and excessive $(\geq 12.0 \mathrm{~kg}$ ). These cutoffs were chosen because appropriate weight gain as defined by the MHLW is $9.0-12.0 \mathrm{~kg}$ for underweight women and 7.0-12.0 kg for normal-weight women. Although appropriate values for overweight women are decided individually, the GWG criterion for overweight pregnant women is basically $5.0 \mathrm{~kg}$. Maternal age was categorized into four groups based on the mean maternal age in years at first delivery in Japan: $<30,30-34$ (reference), 35-39, and $>40$. GWD was calculated as the number of completed weeks of gestation from the first day of the last menstrual period to the date of delivery and was confirmed by earlier ultrasound. We utilized three GWD groups: 36-37 weeks, 38-39 weeks (reference), and 40-41 weeks. BW was categorized into three groups based on the MHLW guidelines: LBW $(<2500 \mathrm{~g})$, normal BW (2500-3999 g), and macrosomia ( $\geq 4000 \mathrm{~g})$.

\section{Ethical considerations}

This study was approved by the Standards of Official Conduct Committee of the Japanese Red Cross Medical Centre in 2012.

\section{Data analysis}

The normality of the data distribution was first assessed using the Kolmogorov-Smirnov test. After this examination, all statistical analyzes were confirmed. The data for maternal age at delivery, GWD, GWG, and BW were described using mean \pm standard deviation (SD). The chi-square test using the expected value was used to assess the differences in pregnancy characteristics among the three BW groups. The differences in the BW categories and GWG, GWD, and pre-pregnancy BMI were analyzed using the Kruskal-Wallis test. The association between pre-pregnancy BMI and maternal age was analyzed by the Kruskal-Wallis test. Differences in infant gender, parity, and BW were evaluated using Mann-Whitney U Test. The relationships between risk of LBW and pregnancy characteristics were analyzed by logistic regression analysis based on the odds ratio (OR) and 95\% confidence interval (CI). P-values less than 0.05 were considered statistically significant. Statistical analysis was performed using Statistical Package (SPSS version 21.0, Chicago).

\section{Results}

\section{Participant demographics}

A total of 2551 pairs of mothers and infants with complete information were included in this study. The demographic characteristics of the women and their infants in the three BW categories are presented in Table 1. Among the women, 567 (22.2\%) were underweight, 1851 (72.6\%) were normal weight, and $133(5.2 \%)$ were overweight. Among the underweight pregnant women, $137(24.2 \%)$ were $<30$ years old, 260 (45.8\%) were $30-34$ years old, 128 (22.6\%) were 35-39 years old, and $42(7.4 \%)$ were $\geq 40$ years old. The mean maternal age at delivery was $34.0 \pm 4.9$ years (range: $16-56$ years). Approximately $40.6 \%$ of the mothers were $\geq 35$ years old. A total of 1580 women (61.9\%) were primiparous and 971 (38.1\%) were multiparous. The mean ages of the primiparous and multiparous women were 33.3 years and 35.1 years, respectively. The pregnant women in the underweight group (mean: $32.7 \pm 4.9$ years, range: $18-48$ years) were significantly younger than those in the normal weight group (mean: $34.3 \pm 4.9$ years, range: $16-54$ years) whereas the women in the overweight group (mean: $35.3 \pm 4.8$ years, range: $23-56$ years $)$ were significantly older $(\mathrm{P}<0.001)$. The proportion of LBW was significantly different among the maternal age groups $(\mathrm{P}<0.05)$. The proportion of LBW in insufficient GWG of the underweight and normal weight groups was significantly higher compared to the overweight group $(\mathrm{P}<0.01)$. The rates of LBW for primiparous mothers and female infants were significantly higher compared to multiparous mothers and male infants $(\mathrm{P}<0.05)$. GWD and GWG differed significantly among the three infant BW categories $(\mathrm{P}<0.001)$. In relation to infant data, $1307(51.2 \%)$ were male and $1244(48.8 \%)$ were female. The number of LBW $(<2500$ g), normal BW (2500-3999g), and macrosomia ( $\geq 4000 \mathrm{~g})$ were 170 (6.7\%), 2357 (92.4\%), and 24 (0.9\%), respectively. The mean BW of all infants was $3056 \pm 382 \mathrm{~g}$. The mean BW of male and female infants were $3105 \pm 381 \mathrm{~g}$ and $3003 \pm 377 \mathrm{~g}$, respectively. The mean BW of male infants was higher than that of female infants $(\mathrm{P}<0.001)$. The mean BW in primiparous and multiparous deliveries was $3032 \pm 376$ $\mathrm{g}$ and $3097 \pm 391 \mathrm{~g}$, respectively. The mean infant BW in multiparous deliveries was higher compared to primiparous deliveries $(\mathrm{P}<0.001)$. The mean infant BW was $2986.7 \pm 370.1 \mathrm{~g}$ in the underweight group, $3069.8 \pm 378.8 \mathrm{~g}$ in the normal weight group, and $3164.7 \pm 446.0 \mathrm{~g}$ in the overweight group. The mean BW differed significantly among the three pre-pregnancy BMI groups $(\mathrm{P}<0.001)$. 
Citation: Arima K, Kasai Y, Sugimoto M, Marui E, Minematsu K (2017) Risk Factors for Low Birth Weight Infants in Japanese Pregnancies: A One-year Study of 2551 Cases in Tokyo. Int J Pediatr Neonat Care 2: 119. doi: https://doi.org/10.15344/2455-2364/2017/122

Page 3 of 6

\begin{tabular}{|c|c|c|c|c|c|c|}
\hline & & \multirow[b]{2}{*}{$\mathrm{n}$} & \multicolumn{3}{|c|}{ Categpries of infant birth weight $(\mathrm{g})$} & \multirow[t]{2}{*}{$\mathrm{P}$-value } \\
\hline & & & $\begin{array}{l}\mathrm{LBW}<2500 \\
\mathrm{n}=170 \\
\mathrm{n}(\%)\end{array}$ & $\begin{array}{l}\text { Normal BW } \\
\mathrm{n}=2357 \\
\mathrm{n}(\%)\end{array}$ & $\begin{array}{l}\text { Macrosomia }>4000 \\
\mathrm{n}=24 \\
\mathrm{n}(\%)\end{array}$ & \\
\hline $\begin{array}{l}\text { Maternal age } \\
\text { (Years) }\end{array}$ & $\begin{array}{l}<30 \\
30-34 \\
35-39 \\
\geq 40\end{array}$ & $\begin{array}{r}468 \\
1047 \\
708 \\
328\end{array}$ & $\begin{array}{c}34(1.3 \%) \\
31.2 \\
61(2.4 \%) \\
69.8 \\
46(1.8 \%) \\
47.2 \\
29(1.1 \%) \\
21.9\end{array}$ & $\begin{array}{c}432(16.9 \%) \\
432.4 \\
981(38.5 \%) \\
967.4 \\
649(25.4 \%) \\
654.2 \\
295(11.6 \%) \\
303.1\end{array}$ & $\begin{array}{c}2(0.1 \%) \\
4.4 \\
5(0.2 \%) \\
9.9 \\
13(0.5 \%) \\
6.7 \\
4(0.2 \%) \\
3.1\end{array}$ & $\mathrm{p}<0.05$ \\
\hline $\begin{array}{l}\text { Pre-pregnancy BMI } \\
\left(\mathrm{kg} / \mathrm{m}^{2}\right)\end{array}$ & $\begin{array}{c}<18.5 \\
18.5-24.9 \\
\geq 25\end{array}$ & $\begin{array}{r}567 \\
1851 \\
133\end{array}$ & $\begin{array}{c}49(1.9 \%) \\
37.8 \\
112(4.4 \%) \\
123.4 \\
9(0.4 \%) \\
8.9\end{array}$ & $\begin{array}{c}515(20.2 \%) \\
523.9 \\
1722(67.5 \%) \\
1710.2 \\
120(4.7 \%) \\
122.9\end{array}$ & $\begin{array}{c}3(0.1 \%) \\
5.3 \\
17(0.6 \%) \\
17.4 \\
4(2.0) \\
1.3\end{array}$ & $\mathrm{p}<0.05$ \\
\hline \multirow[t]{3}{*}{$\begin{array}{l}\text { Pre-pregnancy } \\
\text { BMI/ MHLW } \\
\text { weight gain } \\
\text { guidelines }\end{array}$} & $\begin{array}{c}<18.5 \text { (underweight) } \\
\text { Below } \\
\text { Within } \\
\text { Above }\end{array}$ & $\begin{array}{l}165 \\
229 \\
173\end{array}$ & $\begin{array}{c}24(4.2 \%) \\
14.3 \\
16(2.8 \%) \\
19.8 \\
9(1.6 \%) \\
15.0\end{array}$ & $\begin{array}{c}141(24.9 \%) \\
149.9 \\
213(37.6 \%) \\
208.0 \\
161(28.4 \%) \\
157.1\end{array}$ & $\begin{array}{c}0(0.0 \%) \\
0.9 \\
0(0.0 \%) \\
1.2 \\
3(0.5 \%) \\
0.9\end{array}$ & $\mathrm{p}<0.01$ \\
\hline & $\begin{array}{c}\text { 18.5-25.0 (Average) } \\
\text { Below } \\
\text { Within } \\
\text { Above }\end{array}$ & $\begin{array}{r}265 \\
1110 \\
476\end{array}$ & $\begin{array}{c}38(2.1 \%) \\
16.0 \\
62(3.4 \%) \\
67.2 \\
12(0.6 \%) \\
28.8\end{array}$ & $\begin{array}{c}226(12.2 \%) \\
246.5 \\
1038(56.1 \%) \\
1032.6 \\
458(24.7 \%) \\
442.8\end{array}$ & $\begin{array}{c}1(0.1 \%) \\
2.4 \\
10(0.5 \%) \\
10.2 \\
6(0.3 \%) \\
4.4\end{array}$ & $\mathrm{P}<0.001$ \\
\hline & $\begin{array}{c}\geq 25 \text { (Overweight) } \\
\text { Below } \\
\text { Within } \\
\text { Above }\end{array}$ & $\begin{array}{l}9 \\
32 \\
92\end{array}$ & $\begin{array}{c}1(0.7 \%) \\
0.6 \\
4(3.0 \%) \\
2.2 \\
4(3.0 \%) \\
6.2\end{array}$ & $\begin{array}{c}8(6.0 \%) \\
8.1 \\
28(21.1 \%) \\
28.9 \\
84(63.2 \%) \\
83.0\end{array}$ & $\begin{array}{c}0(0.0 \%) \\
0.3 \\
0(0.0 \%) \\
1.0 \\
4(3.0 \%) \\
2.8\end{array}$ & ns \\
\hline Parity & $\begin{array}{l}\text { primiparas } \\
\text { multiparas }\end{array}$ & $\begin{array}{l}1580 \\
971\end{array}$ & $\begin{array}{c}116(4.6 \%) \\
105.3 \\
54(2.1 \%) \\
64.7\end{array}$ & $\begin{array}{c}1454(57.0 \%) \\
1459.8 \\
903(35.4 \%) \\
897.2\end{array}$ & $\begin{array}{c}10(0.4 \%) \\
14.9 \\
14(0.5 \%) \\
9.1\end{array}$ & $\mathrm{p}<0.05$ \\
\hline Infant gender & $\begin{array}{c}\text { male } \\
\text { female }\end{array}$ & $\begin{array}{l}1307 \\
1244\end{array}$ & $\begin{array}{c}67(2.6 \%) \\
87.1 \\
103(4.0 \%) \\
82.9\end{array}$ & $\begin{array}{c}1226(48.1 \%) \\
12707.6 \\
1131(44.4 \%) \\
1149.4\end{array}$ & $\begin{array}{c}14(0.5 \%) \\
12.3 \\
10(0.4 \%) \\
11.9\end{array}$ & $\mathrm{P}<0.001$ \\
\hline \multicolumn{7}{|l|}{ Mean \pm SD } \\
\hline \multicolumn{3}{|c|}{ Gestational week at delivery (GWD) (weeks) } & $37.9 \pm 1.3$ & $39.3 \pm 1.1$ & $40.4 \pm 0.8$ & $\mathrm{P}<0.001$ \\
\hline \multicolumn{3}{|c|}{ Gestational weight gain (GWG) (kg) } & $8.1 \pm 3.8$ & $10.3 \pm 3.5$ & $12.0 \pm 3.9$ & $\mathrm{P}<0.001$ \\
\hline
\end{tabular}

Table 1: Maternal characteristics dividied into three groups based on the criteria of infant birth weight in Japan

Top row, $\mathrm{n}(\%)$; second row, the expected value

The data of GWD and GWG were shown using mean \pm SD 
Citation: Arima K, Kasai Y, Sugimoto M, Marui E, Minematsu K (2017) Risk Factors for Low Birth Weight Infants in Japanese Pregnancies: A One-year Study of 2551 Cases in Tokyo. Int J Pediatr Neonat Care 2: 119. doi: https://doi.org/10.15344/2455-2364/2017/122

Page 4 of 6

\section{Odds ratio of low birth weight}

Pregnant women in $\geq 40$ years old group were at a1.97-fold higher risk of delivering LBW infants compared to the reference group (3034 years) (adjusted $\mathrm{OR}=1.97 ;$ 95\% $\mathrm{CI}=1.15-3.39$ ) (Table 2). Women who were below the MHLW guideline for GWG $(<7.0 \mathrm{~kg})$ experienced a 2.76-fold increased risk of delivering LBW infants compared to the reference group (9.0-11.0 kg) (adjusted $\mathrm{OR}=2.76,95 \% \mathrm{CI}=1.78-4.29$ ). Women who were less than 37 GWD were at a 9.00-fold higher risk of delivering a LBW infant compared to the reference group (adjusted $\mathrm{OR}=9.00 ; 95 \% \mathrm{CI}=6.06-13.38)$. Multiparous women exhibited a $43 \%$ lower risk of delivering LBW infants (adjusted OR=0.57; 95\% $\mathrm{CI}=0.39-0.83$ ). Compared to pregnant women who delivered male babies, women who delivered female babies exhibited a 2.06 -fold increased risk of LBW (adjusted OR=2.06; 95\% CI=1.45-2.94).

\section{Discussion}

In this study, the participants were classified into four age groups with 30 to 34 years as the reference group. In the USA, the risk of LBW is significantly higher for pregnant women aged 40 years or older compared to women aged 20 to 24 years [10]. In Sweden, advanced maternal age has been associated with an increased risk of LBW and women 35 to 40 years of age delivering singletons have a 1.7-fold higher rate of LBW compared to women 20 to 24 years of age [16]. In this study, the $\geq 40$-year pregnant group had a 1.97 -fold higher risk of delivering LBW babies compared to the 30- to 34-yearpregnant group. Women aged $\geq 40$ years are at elevated risk of LBW, stillbirth, preterm birth, and NICU admission [9]. These results suggest that the risk of delivering LBW babies increases with maternal age. Women should know that their fecundity and fertility begin to decline significantly after 32 years of age [17]. We consider that health education in relation to childbearing and pregnancy at the student periods play an important role to prevent delivering LBW babies.
The mean maternal age at first birth in this study was 33.3 years, which is remarkably high compared to previous studies. The mean maternal age at first birth was 29.2 years in 2005 in Canada, 27.4 years in 2005 in the USA, and 29.5 years in 2006 in England and Wales [9]. The mean maternal age may have been higher in our study because the study was conducted at a center in metropolitan Tokyo where the mean maternal age is significantly higher than in other areas in Japan. In 2013, the mean maternal age at first birth in Japan was 30.4 years; however, in Tokyo the age was 32.2 years [18]. In addition, the mean age at first marriage for females in Japan was 29.3 years but in Tokyo the age was 30.4 years [18]. Thus, we consider delay in first marriage for females as one of the leading causes of the delay of maternal age at first birth.

We studied the effect of maternal age on birth outcomes by parity because increasing maternal age at first birth delays secondborn infants. Although studies have been limited, the risks of child bearing are clearly lower among multiparous women $[9,19]$. There is a positive relationship between maternal age and neonatal death among primiparous but not multiparous women [9]. Our study definitely indicates that the risk of LBW is lower for multiparous compared to primiparous pregnancies. Our analysis verified that the risk of LBW was 2.06-fold higher among female infants compared to male infants. Primiparous women carrying female infants should receive increased monitoring for LBW.

The management of GWG using official guidelines has been implemented globally $[1,2,13,20-23]$. According to a prospective cohort study in the USA, GWG within the levels recommended by the Institute of Medicine (IOM) guidelines was associated with a decreased risk of delivering LBW babies [1]. In Mexico, adequate GWG decreases maternal and infant adverse outcomes [24]. In this study, the proportion of LBW in both underweight and average

\begin{tabular}{|c|c|c|c|c|c|c|c|}
\hline & \multirow{2}{*}{ Measurement } & $\begin{array}{l}\text { More than } 2500 \mathrm{~g} \\
\quad(\mathrm{n}=2381)\end{array}$ & & \multicolumn{4}{|c|}{$\begin{array}{l}\text { LBW (Less than } 2500 \mathrm{~g}) \\
\qquad(\mathrm{n}=170)\end{array}$} \\
\hline & & $\mathrm{n}(\%)$ & $\mathrm{n}(\%)$ & $\begin{array}{c}\text { Univariate analysis } \\
\text { Adjusted odds ratio (95CI) }\end{array}$ & $\mathrm{P}$-value & $\begin{array}{c}\text { Multivariable analysis } \\
\text { Adjusted odds ratio (95CI) }\end{array}$ & $\mathrm{P}$-value \\
\hline Age (years) & $\begin{array}{c}<30 \\
30-34 \\
35-39 \\
>40\end{array}$ & $\begin{array}{l}434(18.2 \%) \\
790(33.2 \%) \\
858(36.0 \%) \\
299(12.6 \%)\end{array}$ & $\begin{array}{l}34(20.0 \%) \\
43(25.3 \%) \\
64(37.6 \%) \\
29(17.1 \%)\end{array}$ & $\begin{array}{c}1.44(0.90-2.29) \\
1.00(\text { Reference }) \\
1.37(0.92-2.04) \\
1.78(1.09-2.91)\end{array}$ & $\begin{array}{c}0.125 \\
- \\
0.121 \\
0.021\end{array}$ & $\begin{array}{c}1.32(0.79-2.20) \\
1.00 \text { (Reference) } \\
1.46(0.94-2.26) \\
1.97(1.15-3.39)\end{array}$ & $\begin{array}{c}0.295 \\
- \\
0.089 \\
0.014\end{array}$ \\
\hline $\begin{array}{l}\text { Pre- } \\
\text { pregnancy } \\
\text { BMI }\left(\mathrm{kg} / \mathrm{m}^{2}\right)\end{array}$ & $\begin{array}{c}<18.5 \\
18.5-24.9 \\
>25\end{array}$ & $\begin{array}{c}518(21.8 \%) \\
1739(73.0 \%) \\
124(5.2 \%)\end{array}$ & $\begin{array}{c}49(28.8 \%) \\
112(65.9 \%) \\
9(5.3 \%)\end{array}$ & $\begin{array}{c}1.47(1.03-2.08) \\
1.00(\text { Reference }) \\
1.13(0.56-2.27)\end{array}$ & $\begin{array}{c}0.031 \\
- \\
0.739\end{array}$ & $\begin{array}{c}1.42(0.96-2.11) \\
1.00(\text { Reference }) \\
0.78(0.36-1.69)\end{array}$ & $\begin{array}{c}0.079 \\
- \\
0.527\end{array}$ \\
\hline GWG (kg) & $\begin{array}{c}<7.0 \\
7.0-8.9 \\
9.0-11.9 \\
>12.0\end{array}$ & $\begin{array}{l}329(13.3 \%) \\
477(20.0 \%) \\
869(36.5 \%) \\
706(29.7 \%)\end{array}$ & $\begin{array}{l}60(35.3 \%) \\
35(20.6 \%) \\
52(30.6 \%) \\
23(13.5 \%)\end{array}$ & $\begin{array}{c}3.05(2.06-4.51) \\
1.23(1.79-1.91) \\
1.00(\text { Reference }) \\
0.54(0.33-0.89)\end{array}$ & $\begin{array}{c}0.001 \\
0.367 \\
- \\
0.017\end{array}$ & $\begin{array}{l}2.76(1.78-4.29) \\
0.95(0.59-1.53) \\
1.00(\text { Reference }) \\
0.59(0.35-1.01)\end{array}$ & $\begin{array}{c}0.001 \\
0.824 \\
- \\
0.056\end{array}$ \\
\hline GWD (weeks) & $\begin{array}{l}36-37 \\
38-39 \\
40-41\end{array}$ & $\begin{array}{c}131(5.5 \%) \\
1172(49.2 \%) \\
1078(45.3 \%)\end{array}$ & $\begin{array}{l}71(41.8 \%) \\
79(46.5 \%) \\
20(11.8 \%)\end{array}$ & $\begin{array}{c}8.04(5.57-11.62) \\
1.00(\text { Reference }) \\
0.28(0.17-0.45)\end{array}$ & $\begin{array}{c}0.001 \\
- \\
0.001\end{array}$ & $\begin{array}{c}9.00(6.06-13.38) \\
1.00(\text { Reference } \\
0.29(0.18-0.49)\end{array}$ & $\begin{array}{c}0.001 \\
- \\
0.001\end{array}$ \\
\hline Parity & $\begin{array}{l}\text { primipara } \\
\text { multipara }\end{array}$ & $\begin{array}{c}1464(61.5 \%) \\
917(38.5 \%)\end{array}$ & $\begin{array}{c}116(68.2 \%) \\
54(31.8 \%)\end{array}$ & $\begin{array}{l}1.00(\text { Reference }) \\
0.74(0.17-0.45)\end{array}$ & 0.081 & $\begin{array}{l}1.00(\text { Reference }) \\
0.57(0.39-0.83)\end{array}$ & 0.003 \\
\hline Infant gender & $\begin{array}{l}\text { male } \\
\text { female }\end{array}$ & $\begin{array}{l}1240(52.1 \%) \\
1141(47.9 \%)\end{array}$ & $\begin{array}{c}67(39.4 \%) \\
103(60.6 \%)\end{array}$ & $\begin{array}{c}1.00 \text { (Reference) } \\
1.67(1.21-2.29)\end{array}$ & 0.002 & $\begin{array}{l}1.00(\text { Reference }) \\
2.06(1.45-2.94)\end{array}$ & $\begin{array}{c}- \\
0.001\end{array}$ \\
\hline
\end{tabular}

Table 2: Odds ratio and 95\% confidence interval of low birth weight.

LBW: low birth weight

GWG: gestational weight gain

GWD:gestational week at delivery

Hosmer-Lemeshow $\mathrm{P}=0.244, \mathrm{P}<0.001$ 
Citation: Arima K, Kasai Y, Sugimoto M, Marui E, Minematsu K (2017) Risk Factors for Low Birth Weight Infants in Japanese Pregnancies: A One-year Study of 2551 Cases in Tokyo. Int J Pediatr Neonat Care 2: 119. doi: https://doi.org/10.15344/2455-2364/2017/122

Page 5 of 6

pregnancies based on MHLW weight gain guidelines was higher. In Japan, low GWG has already been demonstrated to be a valid risk factor for LBW [15]. These results suggest that pregnant women must increase their weight to prevent LBW. Pregnant women must continuously monitor their body weight during pregnancy using their country's official criteria. The differences in the recommended GWG values between Japan and other countries could be due to differences in body composition between races $[2,11,19,23,25]$.

Low pre-pregnancy BMI is a significant risk factor for LBW $[1,2,17]$. According to Japanese epidemiological studies, a decrease in BMI appears to be a major risk factor for the increase in LBW babies $[6,12]$. Our study results are in agreement with these previous studies and it should be noted that not only younger underweight pregnant women but also older underweight pregnant women must be careful In 2013, the percentage of women in their 40s who were underweight in Japan reached $11.0 \%$ [26]. In this study, $13.1 \%$ of women aged $\geq 40$ years were underweight. Efforts should be made to ensure that women are educated about the management of their weight by attending physicians, nurses, and nutritionists to reduce the occurrence of LBW infants. Furthermore, health education from an early stage based on the school is quite important to prevent delivering LBW babies.

Our study suggests that GWD is an important factor to prevent LBW infants. The mean GWD of LBW cases was $36-37$ weeks and this value is lower than that in the other groups of women classified by pre-pregnancy BMI. Extending GWD prevents iatrogenic preterm births and improves neonatal survival rate [27]. Early birth reduces the time in the mother's uterus during which an infant can grow and gain weight and much of the baby's weight is gained during the latter part of pregnancy [28]. According to a large population-based survey of all singleton births in Canada, the risk of preterm ( $<37$ weeks) birth and SGA increases significantly with advanced maternal age [28]. Individualized management of GWG and fetal condition, particularly in older pregnant women, may help prevent the incidence of LBW.

Our study has some potential limitations. It's retrospective nature does not allow us to obtain additional detailed information regarding potential confounding factors such as pregnancy complications $[29,30]$, mode of delivery, maternal education, and lifestyle during pregnancy. Identical anthropometric measurements could not be performed for all pregnant women throughout the research period.

\section{Conclusions}

We have demonstrated that advanced maternal age, early gestational week at delivery, low weight gain during the gestational period, parity, and infant sex are significantly associated with LBW. Strong consideration should be given to the management of pregnant women, particularly those with $\mathrm{BMI}<18.5 \mathrm{~kg} / \mathrm{m}^{2}$, age $>40$ years, or GWG of $<7.0 \mathrm{~kg}$. Primiparous pregnant women and those carrying female infants require more attention in order to improve outcomes. Women should be educated early about childbearing and pregnancy to decrease the rates of LBW.

\section{Competing Interests}

The authors declare that they have no competing interests.

\section{Author Contributions}

Kaori Arima and Kazuo Minematsu were responsible for the study conception and design, and made critical revisions to the paper for important intellectual content. Yasuyo Kasai and Mitsuhiro Sugimoto performed the data collection. Kaori Arima and Kazuo Minematsu were responsible for the drafting of the manuscript and for providing statistical expertize. Eiji Marui supervised the study.

\section{Acknowledgments}

We would like to acknowledge the participants in this study. The authors would like to thank the JRC staff for their expert technical assistance.

\section{References}

1. Frederick IO, Williams MA, Sales AE, Martin DP, Killien M (2008) Prepregnancy body mass index, gestational weight gain, and other maternal characteristics in relation to infant birth weight. Matern Child Health $\mathrm{J}$ 12:557-567.

2. Liu Y, Dai W, Dai X, Li Z (2012) Prepregnancy body mass index and gestational weight gain with the outcome of pregnancy: a 13-year study of 292,568 cases in China. Arch Gynecol Obstet 286: 905-911.

3. Harita N, Kariya M, Hayashi T, Sato KK, Aoki T, et al. (2012) Gestational bodyweight gain among underweight Japanese women related to small-forgestational-age birth. J Obstet Gynaecol Res 38: 1137-1144.

4. Ministry of Health, Labour and Welfare (1982) The National health and nutrition survey 1982, Tokyo: Ministry of Health, Labour and Welfare, Japan.

5. Matsumoto K, Arima K, Komukai J, Danno K, Yoshida H, et al. (2012) The association between smoking and sputum smear-positive pulmonary tuberculosis in Osaka City. Kekkaku 87: 541-547.

6. Ohmi H, Hirooka K, Hata A, Mochizuki Y (2001) Recent trend of increase in proportion of low birthweight infants in Japan. Int J Epidemiol 30: 12691271.

7. Ministry of Health, Labour and Welfare (2006) Guidelines for maternal food life 2006, Tokyo, Ministry of Health, Labour and Welfare, Japan.

8. Takuyo S (2012) The manual of health guideline for low infant birth weight (in Japanese). Osaka Medical Center and Research, Institute for Maternal and Child Health, Japan

9. Lisonkova S, Janssen PA, Sheps SB, Lee SK, Dahlgren L (2010) The effect of maternal age on adverse birth outcomes: does parity matter? J Obstet Gynaecol Can 32: 541-548.

10. Aldous MB, Edmonson MB (1993) Maternal age at first childbirth and risk of low birth weight and preterm delivery in Washington State. JAMA 270: 2574-2577.

11. Reichman NE, Pagnini DL (1997) Maternal age and birth outcomes: data from New Jersey. Fam Plann Perspect 29: 268-272.

12. Terada M, Matsuda Y, Ogawa M, Matsui H, Satoh S (2013) Effects of maternal factors on birth weight in Japan. J Pregnancy 2013: 172395.

13. Cedergren M (2006) Effects of gestational weight gain and body mass index on obstetric outcome in Sweden. Int J Gynaecol Obstet 93: 269-274.

14. Thorsdottir I, Torfadottir JE, Birgisdottir BE, Geirsson RT (2002) Weight gain in women of normal weight before pregnancy: complications in pregnancy or delivery and birth outcome. Obstet Gynecol 99: 799-806.

15. Maruoka K, Yagi M, Akazawa K, Kinukawa N, Ueda K, et al. (1998) Risk factors for low birthweight in Japanese infants. Acta Paediatr 87: 304-309.

16. Cnattingius S, Forman MR, Berendes HW, Isotalo L (1992) Delayed childbearing and risk of adverse perinatal outcome. A population-based study. JAMA 268: 886-890.

17. Johnson JA, Tough S; Society of Obstetricians and Gynaecologists of Canada (2012) Delayed child-bearing. J Obstet Gynaecol Can 34: 80-93.

18. Ministry of Health, Labour and Welfare (2013) Vital statistics of Japan in 2013. Tokyo, Ministry of Health, Labour and Welfare, Japan.

19. Schempf AH, Branum AM, Lukacs SL, Schoendorf KC (2007) Maternal age and parity-associated risks of preterm birth: differences by race/ethnicity. Paediatr Perinat Epidemio 121:34-43. 
Citation: Arima K, Kasai Y, Sugimoto M, Marui E, Minematsu K (2017) Risk Factors for Low Birth Weight Infants in Japanese Pregnancies: A One-year Study of 2551 Cases in Tokyo. Int J Pediatr Neonat Care 2: 119. doi: https://doi.org/10.15344/2455-2364/2017/122

Page 6 of 6

20. Park S, Sappenfield WM, Bish C, Salihu H, Goodman D, et al. (2011) Assessment of the Institute of Medicine recommendations for weight gain during pregnancy: Florida, 2004-2007. Matern Child Health J 15: 289-301.

21. DeVader SR, Neeley HL, Myles TD, Leet TL (2007) Evaluation of gestationa weight gain guidelines for women with normal prepregnancy body mass index. Obstet Gynecol 110: 745-751.

22. Sunsaneevithayakul $P$, Titapant V, Ruangvutilert $P$, Sutantawibul A, Phatihattakorn C, et al. (2014) Relation between gestational weight gain and pregnancy outcomes. J Obstet Gynaecol Res 40: 995-1001.

23. Ee TX, Allen JC Jr, Malhotra R, Koh H, Østbye T, et al. (2014) Determining optimal gestational weight gain in a multiethnic Asian population. $\mathrm{J}$ Obstet Gynaecol Res 40:1002-1008.

24. Reyes E, Martínez N, Parra A, Castillo-Mora A, Ortega-González C (2012) Early intensive obstetric and medical nutrition care is associated with decreased prepregnancy obesity impact on perinatal outcomes. Gynecol Obstet Invest 73: 75-81.

25. Minematsu K, Kaneko $\mathrm{Y}$, Nakazato M, Nnor Jephtha C, Yoda T. et al. (2009) Percentage body fat assessed by bioelectrical impedance analysis as new health index for rural areas in the Asia-Pacific region. Acta Medica Nagasakiensia 54:39-43.

26. Ministry of Health, Labour and Welfare, Japan (2013) The National health and nutrition survey 2013. Tokyo, Ministry of Health, Labour and Welfare, Japan.

27. Chen Y, Zou L, Li G, Ruan Y, Wang X, et al. (2015) [Appropriate delivery mode and timing of termination for pregnancy with low birth weight infants]. Zhonghua Fu Chan Ke Za Zhi 50: 323-328.

28. Widen EM, Factor-Litvak PR, Gallagher D, Paxton A, Pierson RN Jr, et al (2015) The Pattern of Gestational Weight Gain is Associated with Changes in Maternal Body Composition and Neonatal Size. Matern Child Health J 19: 2286-2294.

29. Correa PJ, Vargas JF, Sen S, Illanes SE (2014) Prediction of gestational diabetes early in pregnancy: targeting the long-term complications. Gynecol Obstet Invest 77: 145-149.

30. Aggarawal N, Suri V, Singla R, Chopra S, Sikka P, et al. (2014) Pregnancy outcome in hyperthyroidism: a case control study. Gynecol Obstet Invest 77: 94-99. 